\title{
A visibilidade da atuação de uma enfermeira do Exército Brasileiro a um ferido na $2^{\text {a }}$ Guerra Mundial
}

THE VISIBILITY OF THE CARE GIVEN BY A BRAZILIAN ARMY NURSE TO A WOUNDED SOLDIER DURING WORLD WAR II ANÁLISIS FOTOGRÁFICO DE LAASISTENCIA PRESTADA POR UNA ENFERMERA
DEL EJÉRCITO BRASILEÑO A UN HERIDO EN LA 2ª GUERRA MUNDIAL

\section{Margarida Maria Rocha Bernardes', Gertrudes Teixeira Lopes², Tânia Cristina Franco Santos ${ }^{3}$}

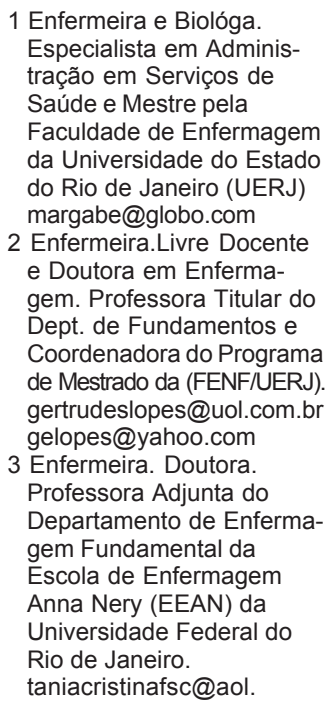

\begin{abstract}
RESUMO
Estudo histórico-sociológico com o objetivo de analisar e descrever a visibilidade da atuação de uma enfermeira do Exército inserida na Força Expedicionária Brasileira (FEB) durante a $2^{\circ}$ Guerra Mundial. Fonte primária: uma fotografia da época, articulada aos depoimentos orais de dezenove agentes. Essa modalidade de obtenção de dados possibilitou criar um método de pesquisa que denominamos Analítico Fotográfico Oral. Escolhemos a foto no acervo iconográfico do Exército localizado no Comando Militar do Leste, no Rio de Janeiro. Fontes secundárias: acervo literário sobre o contexto histórico social da época. Utilizamos os conceitos de habitus, poder e capital cultural de Pierre Bourdieu. Os resultados evidenciaram que para enfrentar o desafio, as voluntárias precisaram adquirir novos habitus mediante treinamento obrigatório, orientado pelos militares para cuidar dos feridos de guerra.
\end{abstract}

\section{DESCRITORES}

História da enfermagem (Brasil). Cuidados de enfermagem.

Pessoal de saúde.

Pesquisa em enfermagem. Guerra.

\begin{abstract}
A historical-sociological study aimed at analyzing and describing the visibility of the performance of a Brazilian Army nurse engaged in the Força Expedicionária Brasileira - FEB (Brazilian Expeditionary Force) during the Second World War. Primary source: a photograph taken at the time, along with the oral testimony of nineteen agents. This mode of gathering data resulted in the creation of a new method of research, which we named Oral-Photographic Analysis. The photo was picked in the Brazilian Army's iconographic collection, located at the Comando Militar do Leste (Eastern Military Command), in Rio de Janeiro. Secondary sources: literature on the sociohistorical context of the period. We used Pierre Bourdieu's concepts of habitus, power and cultural capital. The results showed that, in order to face such challenge and care for the wounded, the volunteer nurses had to acquire new habitus through mandatory training given by the military.
\end{abstract}

\section{KEY WORDS}

History of Nursing (Brazil).

Nursing care.

Health personnel.

Nursing research.

War.

\section{RESUMEN}

Este estudio histórico-sociológico tiene como objetivo analizar y describir la visibilidad de la actuación de una enfermera del Ejército insertada en la Fuerza Expedicionaria Brasileña (FEB) por ocasión de la $2^{\mathrm{a}}$ guerra mundial. Fuente primaria: una fotografía de la época articulada a los testimonios orales de diecinueve agentes. Esta modalidad de obtención de datos posibilitó crear un método de investigación que lo denominamos de Analítico Fotográfico Oral. Escogimos la foto en el acervo iconográfico del Ejército en el Comando Militar del Este en Río de Janeiro. Fuentes secundarias: el acervo literario del contexto histórico social de la época. Utilizamos los conceptos de habitus, poder y capital cultural de Pierre Bourdieu. Los resultados evidenciaron que para enfrentar el desafío, las enfermeras necesitaron adquirir nuevos habitus mediante el entrenamiento obligatorio, orientado por los militares para cuidar a los heridos de guerra.

\section{DESCRIPTORES}

Historia de la enfermería (Brasil). Atención de enfermería. Investigación en enfermería. Personal de salud. Guerra. 


\section{APRESENTAÇÃO}

O conflito da $2^{\text {a }}$ Guerra Mundial aconteceu quando o Brasil vivia politicamente sob a Era Vargas (1930-1945). Este governo criou uma força militar diferenciada com fim específico de participar do conflito mundial, a Força Expedicionária Brasileira (FEB) que partiu para o campo de batalha, comandada pelo General João Batista Mascarenhas de Moraes $^{(1)}$. Nesta Força estava inserido o Batalhão de Saúde composto por 186 profissionais de saúde, entre enfermeiros, médicos e dentistas. Seguiram neste batalhão 67 enfermeiras pioneiras do Exército, sendo 61 enfermeiras hospitalares e 6 especializadas em transporte aéreo ${ }^{(2)}$.

Houve pressão popular, com mobilização civil e militar nacional espontânea para a participação do Brasil neste conflito. Este foi um fator que possibilitou o pioneirismo de enfermeiras nas Forças Armadas. A Enfermagem foi à profissão que propiciou a participação de mulheres nesta mobilização. Os cursos das escolas de formação de Enfermagem da época tiveram procura significativa. $\mathrm{O}$ voluntariado foi feito inclusive pelas princesas brasileiras Maria Francisca e Maria Tereza Orleans e Bragança, que cursaram a Escola de Enfermagem da Cruz Vermelha Brasileira( ${ }^{(2)}$.

A necessidade de criação de um Quadro de Enfermeiras para atuar no cenário da guerra, juntamente com o efetivo da FEB, se deu em função de uma solicitação dos aliados: '"[...] as [enfermeiras deles] já estavam muito cansadas e, além do mais, não falavam a nossa língua [português][...]”(3).

Portanto, o governo brasileiro implementou em caráter de urgência a busca de voluntárias, de modo a atender a solicitação de um grupo hegemônico, "[...]mandatários do Estado, detentores do monopólio de violência simbólica legítima"(4)

As enfermeiras brasileiras foram selecionadas após terem iniciado seu voluntariado no esforço de guerra em 9 de outubro de 1943, com chamada publicada no jornal "O Globo"(5).

Todas participaram, em caráter obrigatório do Curso de Emergência de Enfermeiras da Reserva do Exército (CEERE) ministrado pela Diretoria de Saúde do Exército. Segundo o depoimento oral do General Jonas Correia Neto, as enfermeiras ao terminarem o CEERE, integrando-se à FEB tornaramse enfermeiras da reserva. A partir do momento em que integraram essa força operacional, de combatentes, imediatamente passaram a ativa, como todo o pessoal da reserva convocado "[...]Todo esse pessoal passou a estar na ativa por causa da guer- ra[...]" O objetivo deste Curso era formar o Quadro de Enfermagem (QEERE), que foi criado pelo Decreto-Lei n ${ }^{\circ}$ 6097/43 de 13 de Dezembro de 1943, publicado no Diário Oficial da União n ${ }^{\circ} 290$, datado de $15 / 12 / 43^{(6)}$. Tal curso comportou três módulos distintos: parte teórica, preparação física e instrução militar ${ }^{(5)}$.

O treinamento oferecido teve o intuito de representar uma estratégia de homogeinização do comportamento das candidatas, mediante a absorção de um habitus militar e, possibilitar-lhes enfrentar o cenário de guerra, com todas as implicações que pudessem advir de um evento dessa natureza.

Define-se habitus como sendo resultado do conhecimento adquirido, uma disposição incorporada duradoura e transferível, vinda de um longo período de aprendizado, produto do contato com as diversas estruturas sociais ${ }^{(7)}$. Esclarece que os diversos esquemas de percepção, avaliação e ação, são constitutivos do habitus.

Acreditamos que a preparação para a guerra gerou uma mudança significativa no habitus das jovens, ao se apropriarem da formação militar e, precisaram demandar esforços para adaptarem-se à Força Armada que passaram a pertencer, além de inserirem-se numa equipe multiprofissional de cultura diversa.

Diante do exposto, deriva como objetivo analisar e descrever a visibilidade da atuação de uma enfermeira do Exército inserida na FEB, durante a $2^{\circ}$ Guerra Mundial.

\section{METODOLOGIA}

Para esse estudo de natureza histórico-social utilizamos uma foto, considerada por nós emblemática, retirada de um acervo de mais de cinco mil fotos, pertencente ao Exército Brasileiro. Resolvemos iniciar as escolhas pelas fotos que concretamente nos ajudariam a descrever a trajetória das nossas enfermeiras. Entrevistamos 9 enfermeiras e dez militares, que assinaram o Consentimento Livre e Informado e o Termo de Doação de Depoimento. Os testemunhos das enfermeiras foram filmados, gravados e transcritos, os dos militares apenas não foram filmados.

Objetivando a compreensão da fotografia e do momento vivido, articulamos a nossa análise com os depoimentos dos sujeitos, sobre a fotografia apresentada. Os resultados dos depoimentos orais equipararam-se em importância à análise da fotografia apresentada, equilibrando a abordagem feita
A visibilidade da atuação de uma enfermeira do Exército Brasileiro a um ferido na $2^{\mathrm{a}}$ Guerra Mundial 
Margarida M. R. Bernardes Gertrudes Teixeira Lopes Tânia Cristina F. Santos pelas autoras através de dois métodos de pesquisa consagrados: História Oral e Análise Fotográfica. Em vista disso, o depoimento oral e a fotografia passaram a ser as fontes preferenciais do estudo.

A articulação dos depoimentos orais com a fotografia permitiu a obtenção de dados inéditos não registrados em fontes oficiais. Esses procedimentos empregados na busca e análise das informações vislumbraram uma nova maneira de revitalização da memória durante a entrevista e pode oferecer, uma inusitada possibilidade de pesquisa histórica.

Esta forma de articular o texto fotográfico com os depoimentos e os documentos, na pesquisa histórica, se apresenta como método de investigação que possibilita ao pesquisador lançar mão de diferentes técnicas para aprofundar o conhecimento sobre um determinado fenômeno em estudo. Denominamos o método desenvolvido de Método Analítico Fotográfico Oral.

Ao desenvolvermos esta experiência, tínhamos em mente aproximar-nos ao máximo das experiências vivenciadas pelas enfermeiras do Exército no Teatro de Operações durante a $2^{\circ}$ Guerra Mundial. Ao nos desafiarmos neste caminho metodológico, não nos dávamos conta de que estávamos ao mesmo tempo desenvolvendo uma nova maneira de pesquisar em história. Assim, esperamos que este novo método possa contribuir com outros pesquisadores no desvelamento de fenômenos vinculados a essa área de conhecimento.

O material selecionado foi submetido à análise de acordo com o seu conteúdo manifesto. A articulação do texto fotográfico aos depoimentos orais favoreceu a interpretação dos dados.

Os achados foram analisados à luz dos conceitos de habitus, poder e capital cultural, desenvolvidos pelo sociólogo Pierre Bourdieu.

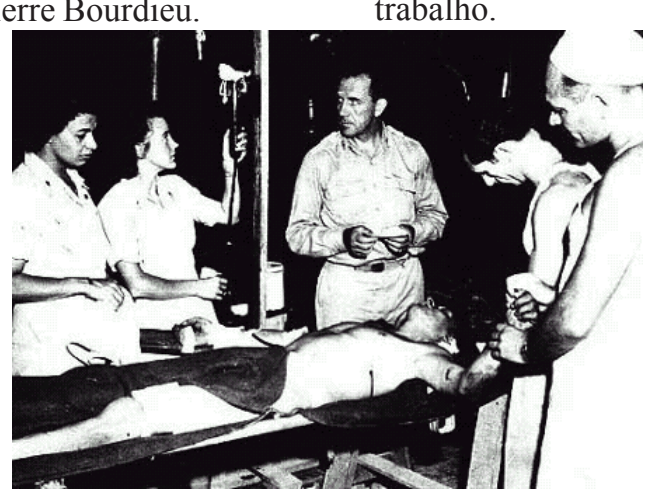

Registro fotográfico da assistência multiprofissional prestada por uma equipe mista brasileira e norte-americana em uma enfermaria de choque, na Itália. Localização: 5 ${ }^{a}$ Seção do C.M.L., Subseção de Audiovisuais.

\section{A PARTICIPAÇÃO DA ENFERMEIRA BRASILEIRA NO CUIDADO AO FERIDO DE GUERRA}

Toda a tropa brasileira, nela inclusas as enfermeiras, foi obrigada a deter abruptamente uma concentração de todos os tipos de capital: “[...] econômico, político, militar, cultural, científico e tecnológico, fundamento de uma domina-

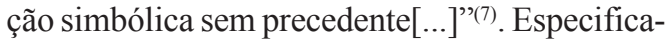
mente em relação às agentes dessa pesquisa, está claro que rapidamente, por imposição norte-americana essas moças brasileiras foram selecionadas e preparadas para enfrentar uma guerra, num país distante, desconhecido para a maioria delas, sendo obrigadas a absorver além de outras culturas, diferentes da sua, novas tecnologias para desenvolver seu trabalho de profissional de Enfermagem, compondo a equipe norte-americana melhor preparada e organizada, num tempo ímpar e recordista.

Prestar assistência multiprofissional a pacientes aparentemente chocados, como o da foto em tela, atuando em equipes mistas com outros profissionais norte-americanos foi, sem dúvida alguma, uma das lutas enfrentadas por esse grupamento feminino estudado. A foto tem como tema o trabalho de uma equipe de saúde e contempla, com seu olhar social e científico, o universo do trabalho nobre do cuidado humano. É um retrato onde se vêem figuras humanas, numa tentativa de romper com a passagem transitória da vida, imortalizando-se através da imagem. Esse momento aqui congelado, seguramente possui algo que levou os agentes a serem registrados em conjunto, profissionais homens e mulheres aliados e unidos numa ação técnica e prática de socorro, fazendo jus ao juramento de salvar vidas, prestado durante a aquisição de seu capital cultural específico, dando idéia da intervenção da ciência médica e das difíceis condições de trabalho. 
Deduz-se que o espaço fotografado não é o Brasil por se tratar do registro de um momento congelado dominado pela atuação de profissionais de saúde, explicitando uma ação de enfermagem e médica, com pessoas já identificadas pelas enfermeiras deste estudo e que só se encontraram nos Hospitais do Teatro de Operações (T.O) na Itália, tendo como cenário uma enfermaria de choque, segundo descrição posterior das depoentes.

A equipe de saúde presente na foto é composta de cinco profissionais e todos expressam em suas fisionomias preocupação e tensão. Se olharmos as expressões dos retratados, veremos que foram adotadas diferentes posturas frente à máquina fotográfica. Eles não estão olhando para a objetiva. A hegemonia médica se reflete pela presença desse profissional à cabeceira do ferido, no centro da fotografia de onde emanam as ordens, sabendo-se antecipadamente que a pessoa de maior poder sempre se localiza no centro ou nas cabeceiras das ações. Todos estão com os semblantes graves, demonstrando a seriedade do seu trabalho, naquela que seria sua atividade concreta naquele cenário, ou seja, assistir/ cuidar dos feridos de Guerra.

Confirmando que são profissionais ligados à área de saúde, podemos observar o equipamento de hemotransfusão colocado em um suporte. Esse equipamento está sendo manipulado pela enfermeira norte-americana Miss Mary, segunda figura da esquerda para a direita da fotografia, ladeada pela enfermeira brasileira Lúcia Osório, que tem nas mãos uma toalha, o que demonstra sintonia em termos de assistência de Enfermagem. O grupo está disposto em forma de L, formando um ângulo de $90^{\circ}$ graus. No vértice encontram-se as figuras centrais, o homem ferido e o oficial médico, quarta e quinta figuras da esquerda para a direita da composição, estão paramentados com aventais, significando a mesma função no ato, estando um deles com touca, o que caracteriza o estado de prontidão para o trabalho. O pulso do ferido está sendo aferido pelo profissional que está com a touca na cabeça. $\mathrm{O}$ ferido, posicionado deitado em padiola característica da guerra, está sendo cuidado por um corpo clínico composto de enfermeiras e médicos, provavelmente já tendo recebido os primeiros socorros por estarem aparentes curativos em sua perna esquerda e abdome. Há um sangramento em seu tórax e sua fisionomia denota prostração. A posição ereta da equipe, reflete o poder inerente da mesma sobre o paciente exposto.

A presença da equipe de saúde está destacada e faz contraste com o fundo escuro da enfermaria, realçando suas imagens e despertando a atenção do espectador para as ações dos profissionais.
As mulheres usam uniformes iguais, mostrando que compartilham o mesmo tipo de atividade. $\mathrm{O}$ uso do uniforme norte-americano foi uma decisão objetiva e conciliadora frente aos uniformes brasileiros inadequados. Tal fato pode ser caracterizado como "[...]vantagens simbólicas[...]"(4), recebendo as brasileiras um uniforme reconhecido, associado a uma imagem de modernidade.

Acredita-se que o primeiro sinal de vida que os soldados feridos identificavam ao recuperarem a consciência nos hospitais, era a visão de enfermeiras com seus típicos uniformes, parecendo sempre exaustas e ocupadas, mas eram moças com sorrisos maravilhosos e reconfortantes, portadoras de “[...]índole reanimadora e mãos gentis[...]" ${ }^{\text {(8) }}$. Significando para os soldados feridos nas batalhas seres especiais.

No que tange ao cenário, o depoimento desta enfermeira esclarece:

[...]Essa fotografia foi feita na sala de choque, no Hospital de Evacuação[...]As equipes eram mistas com as americanas[...]Aqui está a Lúcia Osório e a enfermeira americana Miss Mary. Chegavam pacientes em choque, entrávamos em conjunto brasileiras e americanas (Enfermeira Virgínia Portocarrero).

\section{Para a Enfermeira Bertha Moraes:}

[...]a função do hospital de Evacuação era de colocar o paciente em condições de viagem para a retaguarda[...]tínhamos que trabalhar muito e muito rápido[...]a rotina do hospital era muito dura[...]quando o paciente chegava[...]só tinha recebido na linha de frente aquele grãozinho de morfina[...]ali era acudido, socorrido, limpo[...]então ele era posto em condições de viajar[...]as enfermeiras trabalhavam muito[...].

Prosseguindo o relato abaixo complementa:

[...]é uma enfermaria das mais importantes que existiam[...]é o choque, enfermaria de choque[...]No choque você não tinha camas, só cavaletes[...]o choque é o pronto socorro[...]o paciente ficava ali [...]era prestado o primeiro socorro[...]nessa enfermaria de choque trabaIhavam duas equipes, brasileiras e americanas (Enfermeira Elza Cansanção Medeiros).

Esta fala nos remete à luta para a comunicação verbal, no convívio diário profissional e pessoal no T.O., considerando a nacionalidade dos sujeitos da foto. Como estratégia para melhorar a convivência e sintonia profissional que idealmente deveria existir, os agentes utilizaram o "senso prático", assim descrito: “[...]o senso prático pede que se aprendam as técnicas e as estratégias da co-
A visibilidade da atuação de uma enfermeira do Exército Brasileiro a um ferido na $2^{\text {a }}$ Guerra Mundial 
Margarida M. R. Bernardes Gertrudes Teixeira Lopes Tânia Cristina F. Santos municação[... $]^{\prime \prime(9)}$. Concordamos com o autor quando esclarece que estas estratégias são forças simbólicas.

A luta das enfermeiras nesta foto, mostra o trabalho em equipe interprofissional e as atividades específicas da profissão inclusas no capital cultural da enfermeira.

$\mathrm{Na}$ foto existe a parceria entre a equipe de saúde objetivando a vida do paciente. Esta foto foi publicada num jornal brasileiro ("Tribuna Popular", Rio de Janeiro, datado de 12/07/1945, n45anoI) divulgando o trabalho desempenhado por uma enfermeira numa equipe multiprofissional cuidando de um ferido de guerra. Este fato nos oportuniza salientar que: "[...] tal empreendimento utiliza a imprensa e você utiliza a imprensa para

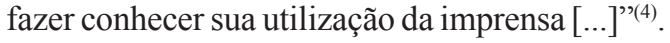

Ratifica-se o exposto, afirmando que o médico do hospital avançado de campanha era aquela pessoa mais dedicada que poderia existir, trabalhava durante muitas horas sem a disponibilidade de recursos adequados, acrescenta que "[...] as maravilhosas enfermeiras faziam a mesma coisa $[\ldots]^{\prime \prime}(7)$.

Complementando o mesmo autor descreve os afazeres das enfermeiras afirmando que trocavam os curativos, checavam prontuários, administravam medicamentos, monitoravam os sinais vitais, fazendo paralelamente a isso a rearrumação das cobertas, ofertando ainda um sorriso ao ferido. Afirma que elas ocupavam-se demais com o tratamento com plasma sangüíneo, sulfa e penicilina. Cita que às 19 horas, era misturada toda a penicilina necessária para a primeira ronda de aplicação. Uma enfermeira, acompanhada de dois técnicos percorriam o hospital para administrá-la, num ritmo de sessenta pacientes por barraca. Considera o autor que era uma verdadeira arte, encontrar os caminhos durante a noite, sem iluminação, nem mesmo lanterna, nas barracas vagas e sem distinção de silhuetas em contraste com a escuridão, com cordas e cravos de barracas, numa ameaça constante, com as seringas e os medicamentos sendo equilibrados nos braços de forma precária.

A expressão da enfermeira retratada Lúcia Osório expressa a visão que as enfermeiras, objeto desse estudo deixaram para os agentes da nossa FEB, transcrito nesse trecho do depoimento de seu Comandante, o Marechal Mascarenhas de Moraes $^{(10)}$.
[...]Coube à nossa enfermeira, além de sua missão profissional, representar as virtudes da mulher brasileira, entre homens e mulheres de várias nacionalidades, no convívio cotidiano dos hospitais americanos. As nossas compatriotas que acorreram ao chamado da Pátria, prestaram excelentes serviços à F.E.B., durante a sua permanência em território italiano, enfrentando e vencendo obstáculos numerosos. Ainda no Brasil, sofreram a maledicência impatriótica de alguns. Na Itália, viveram e serviram em hospitais americanos, onde, além das dificuldades advindas das diferenças de idiomas e hábitos, suportaram por algum tempo a inferioridade hierárquica e pecuniária em relação às suas colegas americanas, com quem conviviam. Não obstante os óbices encontrados, as enfermeiras incorporadas à F.E.B. atenderam com abnegação e proficiência os nossos feridos e doentes, dando um veemente e nobilitante testemunho do valor da mulher brasileira.

Portanto, a luta das enfermeiras nesta foto, mostra o trabalho em equipe interprofissional $\mathrm{e}$ as atividades específicas da profissão inclusas no capital cultural da enfermeira.

As fotografias inegavelmente foram instrumentos de comunicação da Guerra. Porém, elas não ficaram restritas às imagens daquele evento, registraram também a intervenção social desse saber, através do poder simbólico que emana da posição ocupada pelos agentes. "[...] A imagem faz parte de uma prática médicofotográfica $[\ldots]^{\prime ’(11)}$.

\section{CONSIDERAÇÕES FINAIS}

A participação das enfermeiras no cenário da $2^{\text {a }}$ Guerra Mundial foi decorrente da pressão dos aliados norte-americanos ao governo brasileiro, no sentido de exigir enfermeiras na força tarefa que seguiu para o Teatro de Operações.

A entrada das enfermeiras nesta guerra foi importante para a afirmação da Enfermagem moderna conforme o sistema Nigthingale. Representou a persuasiva imagem da pátria mãe que estendia os cuidados (maternos) aos seus filhos no front de guerra ${ }^{(12)}$.

Um traço marcante do preparo dessas enfermeiras voluntárias foi o exaustivo investimento nos aspectos inerentes ao treinamento profissional, preparo físico e a assimiliação de um habitus militar. Tais estratégias tiveram a função de fortalecer o sentimento de unidade interna do grupo, mediante a homogeneização de atitudes e ges- 
tos, assim como de possibilitar-lhes atuar na equipe de saúde norte-americana em parceria com as enfermeiras desse país.

Certamente apesar de todos os obstáculos encontrados, os depoimentos emocionados que ouvimos das agentes enfermeiras e de militares que lá serviram, nos permitem concluir que o texto fotográfico dá visibilidade a atuação conjunta das enfermeiras brasileiras e norte-americanas no atendimento ao ferido, no cenário da $2^{\circ}$ Guerra Mundial. Se as guerras tem uma face cruel e desumana, o trabalho da Enfermagem é indiscutivelmente a face humana de um conflito.

\section{REFERÊNCIAS}

(1) Silveira JX. A FEB por um soldado. Rio de Janeiro: Expressão e Cultura; 2000.

(2) Medeiros EC. Eu estava lá! Rio de Janeiro: Ágora da Ilha; 2001.

(3) Medeiros EC. 1...2...Esquerda...Direita!...Acertem o passo. Alagoas: Cian; 2003.

(4) Bourdieu P. Livre troca: diálogos entre ciência e arte. Trad. de Paulo Cesar da Costa Gomes. Rio de Janeiro: Bertrand Brasil; 1995.

(5) Motta \& Silva GLN. Tomo 6. In: Motta A. de M, organizador. História oral do Exército na Segunda Guerra Mundial. Rio de Janeiro: Biblioteca do Exército; 2001.

(6) Brasil. Exército Brasileiro. Estado Maior. Estatuto dos militares: lei nº 6880. Brasília: EGGCF; 1997.

(7) Bourdieu P. Contrafogos 2: por um movimento social europeu. Trad. de André Telles. Rio de Janeiro: Jorge Zahar; 2001.
(8) Ambrose SE. Soldados cidadãos: do desembarque do Exército Americano nas praias da Normandia à batalha das Ardenas e a rendição da Alemanha, 7 de junho de 1944 a 7 de maio de 1945. Trad. de Milton Chaves de Almeida. Rio de Janeiro: Bertrand Brasil; 2001.

(9) Bourdieu P. O poder simbólico. $2^{\mathrm{a}}$ ed. Rio de Janeiro: Bertrand Brasil; 1998.

(10) Moraes JBM. A F.E.B. pelo seu Comandante. São Paulo: Instituto Progresso Editorial; 1947.

(11) Thielen.EV. Imagens da saúde do Brasil. A fotografia na institucionalização da Saúde Pública. [dissertação]. São Paulo (SP): Pontifícia Universidade Católica de São Paulo; 1992.

(12) Cytrynowicz R. A serviço da pátria: a mobilização das enfermeiras no Brasil durante a $2^{\text {a }}$ Guerra Mundial. Hist, Ci, Saúde [periódico online] 2000; 7(1):73-91. Disponível em: $<$ http://www.scielo.br/ scielo.php?script $=$ sci_arttext\&pid $=$ S 0104 $59702000000200004 \& \operatorname{lng}=\mathrm{en} \& \mathrm{nrm}=\mathrm{iso} \& \operatorname{lng}=\mathrm{pt}>$ (08 jul. 2004).
A visibilidade da atuação de uma enfermeira do Exército Brasileiro a um ferido na $2^{\mathrm{a}}$ Guerra Mundial 